\title{
Laboratory tests for the optimization of mesh size for flexible debris-flow barriers
}

\author{
C. Wendeler ${ }^{1, \mathrm{a}}$ and A. Volkwein ${ }^{1}$ \\ ${ }^{1}$ WSL Swiss Federal Institute for Forest, Snow and Landscape Research, Zuercherstr. 111, 8903 Birmensdorf, Switzerland \\ anow at: Geobrugg AG Protection Systems, Aachstr. 11, 8590 Romanshorn, Switzerland \\ Correspondence to: A. Volkwein (volkwein@wsl.ch)
}

Received: 10 February 2015 - Published in Nat. Hazards Earth Syst. Sci. Discuss.: 31 March 2015

Revised: 22 September 2015 - Accepted: 17 November 2015 - Published: 2 December 2015

\begin{abstract}
Flexible barriers can be used within channelized riverbeds as an effective and efficient alternative to protect from debris flows. Their retention capability strongly depends on the size of the mesh openings and the gap between the lower barrier edge and the channel's floor. The question is now whether there is a relation between the grain size distribution of the debris material and the openings of a flexible barrier. Small-scale laboratory tests were performed to study these loading aspects of flexible debris-flow barriers for the Milibach river (Canton Berne, Switzerland). In situ debris material has been used to quantify the influence of different mesh sizes and the gap between the lower barrier edge and the riverbed compared to the $d_{90}$ grain size and the flow height, where $d_{90}$ is the maximum diameter of $90 \%$ of the grains. It was possible to study the filling process and the retaining behaviour of the barriers as a function of the mesh size. A reasonable retention was reached with the net having a mesh size and a basal gap smaller than or equal to $d_{90}$. These relations could be transferred to the field. A dimensional analysis reveals possible dimensionless numbers that can be used to scale the laboratory results. The findings are supported by the results of similar laboratory tests using debris material from different locations and by the available field measurements.
\end{abstract}

\section{Introduction}

Flexible debris-flow barriers derived from rockfall and snowslide protection systems are an innovative protection measure against small- and medium-sized debris flows (see example in Fig. 1). The flexibility of the system enables a soft stop of the impacting material by providing an elongated braking distance. The typical net structure is light compared to concrete check dams and can be installed in mountain regions, even without using a helicopter. The main retention mechanism of such barriers is the dewatering of the debris through the net structure forming a kind of dam that in turn stops the following debris.

Designing a debris-flow barrier according to, for example, Wendeler (2008) or Volkwein (2014) also includes aspects regarding the capability of the barrier to retain the impacting debris material: apart from loads acting on the components also the geometry of the openings of the barrier's mesh and the gap between the barrier and the riverbed play a significant role. If the openings are too large no material is retained. If they are too small, clogging occurs prematurely without any possibility of letting fine material pass through and draining the retained debris.

In the study presented here the opening sizes are investigated for a flexible debris-flow barrier in the Swiss Milibach river (Monney et al., 2007; Schatzmann, 2006; Roth et al., 2006). For the study, small-scale laboratory tests were expected to deliver results that can then be upscaled to the field. Six laboratory tests with debris-flow material taken from the river Milibach were carried out with net barriers of different mesh sizes and with basal gaps between the lower net edge and the channel bed in relation to the grain size distribution.

To investigate the loading aspects of debris-flow barrier systems, laboratory tests as described in Canelli et al. (2012), Moriguchi et al. (2009), or Wendeler (2008) are useful. However, special care is necessary when upscaling the results of laboratory tests to the field (O'Brien and Julien, 1988; Schatzmann, 2005; Gubler, 2007; Iverson, 2015). The lab- 


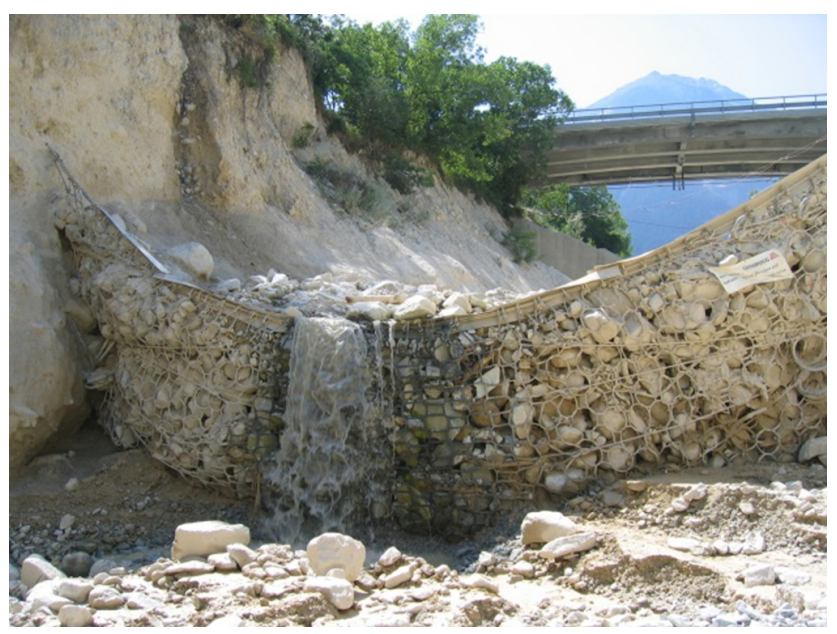

Figure 1. Filled debris-flow barrier in the Illgraben, Switzerland (Wendeler, 2008).

oratory chute of the Swiss Federal Research Institute WSL (Weber, 2000) enables tests with artificial debris flows from natural debris material impacting different barrier systems. Wendeler (2008) used this chute to examine different mesh stiffness's and mesh sizes in 60 tests with material from the Swiss river Illgraben and from the Trachtbach torrent. The tests also allowed one to study the stopping and overtopping processes of the barriers, and their results were also used to support the six tests presented in this study. The multiple tests also allowed the creation of a database that helps in the dimensional analysis presented in Sect. 4.1. In this section, relevant dimensionless numbers are explained and their range is found for laboratory tests and field measurements as shown.

\section{Test details}

Above the two villages of Hasliberg and Meiringen in Switzerland the river Milibach is fed by the rivers Louwenenbach and Schlüochtbach. The narrow valley of the river Schlüochtbach is mainly composed of moraine material whereas that of the river Louwenenbach is composed of strongly weathered schist material as shown in Fig. 2. The debris-flow material was taken from the Louwenenbach river and transported by helicopter and truck. Block sizes up to $1.25 \mathrm{~m}$ are found in the debris, whereas the $d_{90}$ grain size is estimated to be around $0.3-0.5 \mathrm{~m}$.

The laboratory chute consists of two main parts. The first one is a $0.15 \mathrm{~m}^{3}$ start reservoir followed by an acceleration section. The second part is a $3.88 \mathrm{~m}$ long and $30 \mathrm{~cm}$ wide channel in which velocity and flow height measurements are carried out (see Fig. 3). Four laser devices are installed along the channel to measure the current flow height (Fig. 4). The data sample rate of $2.2 \mathrm{kHz}$ allows the detection of fast passing objects and also captures the debris-flow front properly.

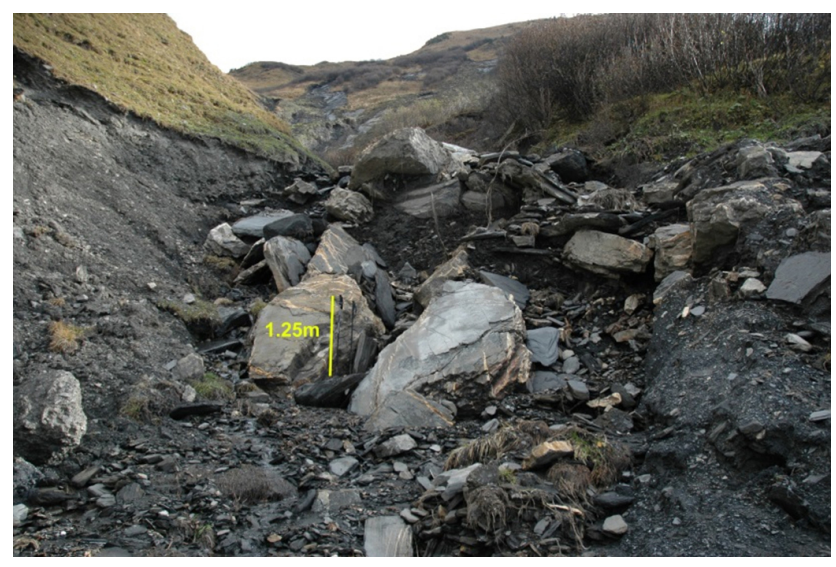

Figure 2. The schist material in/of the Louwenenbach riverbed.

(a)

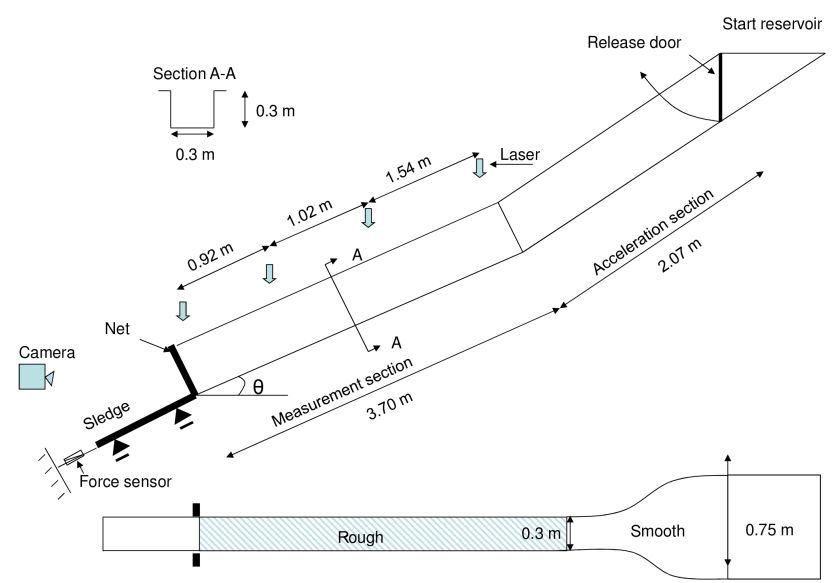

(b)

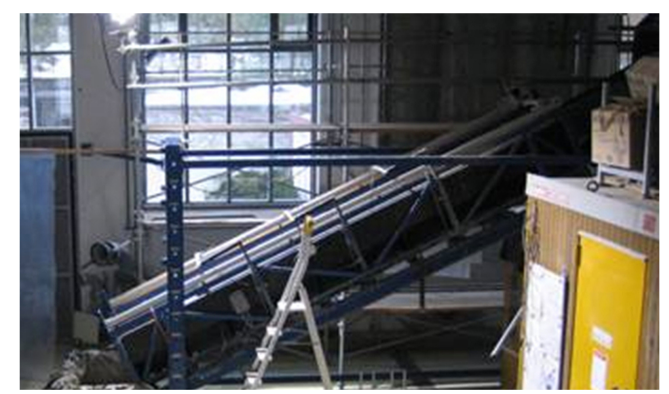

Figure 3. (a) Layout of the chute with its variation of the inclination and (b) photograph of the chute at the WSL laboratory.

The local velocity of the front is back-calculated from the front arrival and the time span between the laser devices.

A so-called "sledge" is situated at the lower end, in front of the channel, which is axially supported. On this sledge different types of barrier can be installed (Fig. 5). Two load cells measure the forces in the flow direction during the impact.

To obtain a redundant confirmation of the impact velocity, high-speed cameras are placed on top of and in front of the 

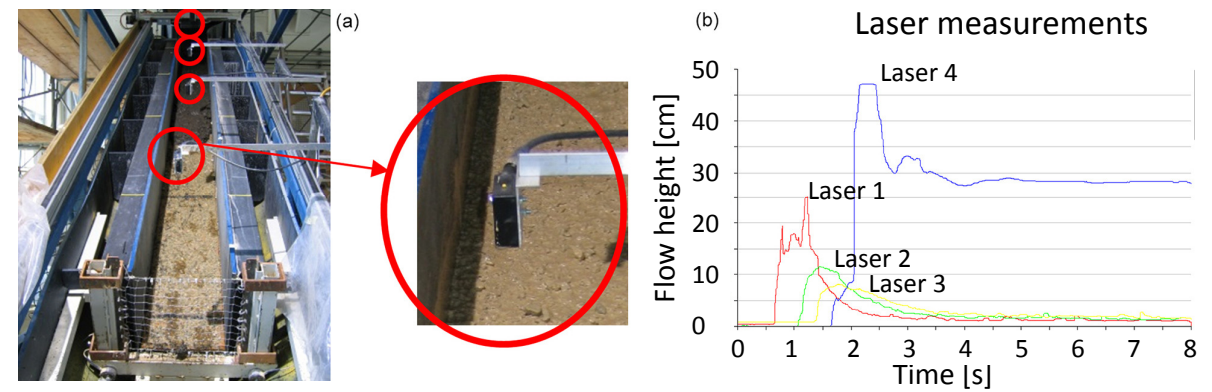

Figure 4. (a) Four laser devices along the channel measuring the flow height and allowing the determination of the front velocity. (b) Example diagram of the measuring results of a debris flow passing the four laser devices. The blue curve corresponds to the laser installed on top of the barrier. It measures the filling height.

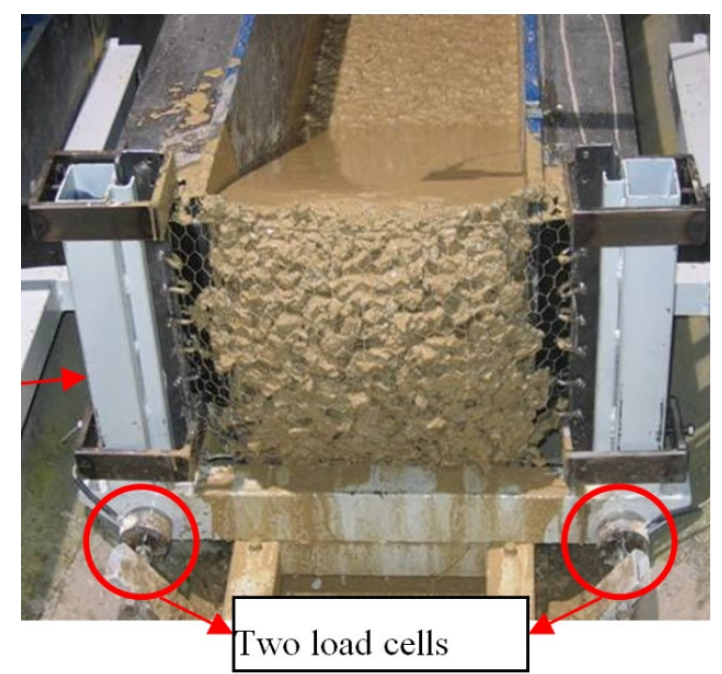

Figure 5. Photograph of the sledge in front of the chute with load cells and a filled barrier.

sledge to record the filling process. Their images are postanalysed over time. After the test, a laser device mounted on a linear guide unit scans the topography of the channel and the filled barrier with a raster size of $7.5 \mathrm{~mm}$ in the longitudinal and transversal directions. From this raster data a topographic map of the retained debris-flow volume (Fig. 6) and the cone inclination behind the barrier can be calculated.

Each laboratory test is carried out as follows: first, a certain amount of debris is mixed with water in a concrete mixer. The mixture is then placed in the release box of the laboratory chute. Then an immediate release of the material takes place to avoid segregation of the mixture. To ensure the complete release of all the material, the front wall of the box opens at once. This action also triggers the measuring system.

At the lower end of the chute, the mixture is caught by the installed barrier. The front speed and deposition mass balance are analysed afterwards. The barriers used for the tests were made from small rope nets that usually can be found for the goals of ball games.

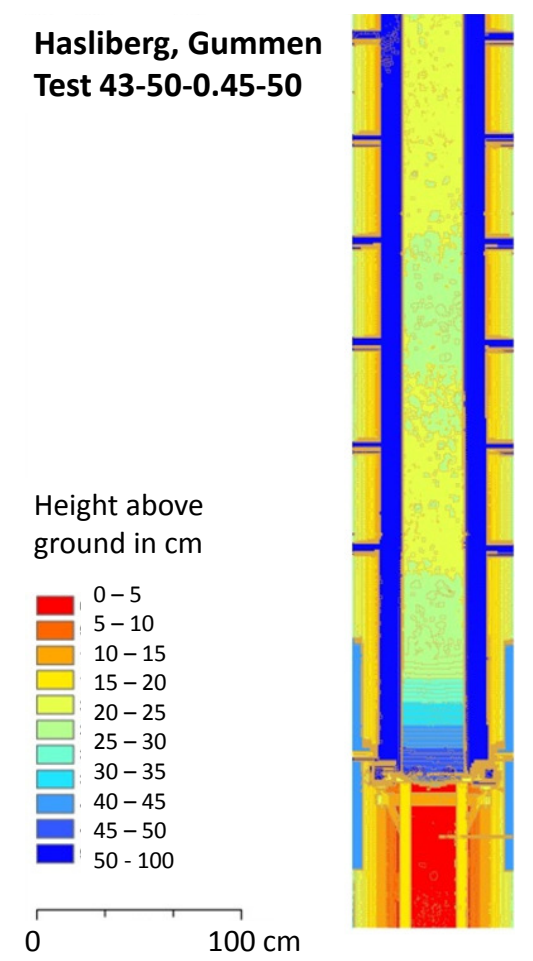

Figure 6. Topographic profile of the channel after test 43.

The numbering of the tests follows the naming convention $a-b-w-V$, where $a$ is the test number, $b$ describes the chute's inclination in percent, $w$ is the volumetric water content and $V$ is the material volume in litres (e.g. 01-55-0.30-100).

The determination of the volumetric water content $w$ of test mixtures requires the prior determination of the residual gravimetric moisture of the solid material before the test by drying the material for $24 \mathrm{~h}$ at $105^{\circ} \mathrm{C}$ and weighting it before and after. The resulting mass difference $m$ in relation to the initial solid mass represents the gravimetric residual water content $w_{\mathrm{R}}$. The necessary masses of solids $m_{\mathrm{S}}$ and water $m_{f}$ for a given total volume $V$ and with the desired volumetric water content $w$ of the mixtures are then determined 
Table 1. Test run overview.

\begin{tabular}{lllll}
\hline Test* & Mesh size/basal gap & Water content & Retained volume & Comments \\
\hline $40-50-0.40-50$ & $3 \mathrm{~cm} /-$ & $40 \%$ & - & Debris flow stopped before barrier \\
$41-50-0.50-50$ & $3 \mathrm{~cm} /-$ & $50 \%$ & $30 \mathrm{dm}^{3}$ & Muddy debris flow \\
$42-50-0.45-50$ & $3 \mathrm{~cm} /-$ & $45 \%$ & $30 \mathrm{dm}^{3}$ & Typical debris-flow front \\
$43-50-0.45-50$ & $3 \mathrm{~cm} / 3 \mathrm{~cm}$ & $45 \%$ & $30 \mathrm{dm}^{3}$ & Typical debris-flow front \\
$44-50-0.45-50$ & $3 \mathrm{~cm} / 6 \mathrm{~cm}$ & $45 \%$ & - & Typical debris-flow front \\
$45-50-0.45-50$ & $4 \mathrm{~cm} /-$ & $45 \%$ & $25 \mathrm{dm}^{3}$ & Typical debris-flow front \\
$46-50-0.45-50$ & $6 \mathrm{~cm} /-$ & $45 \%$ & $22 \mathrm{dm}^{3}$ & Typical debris-flow front \\
\hline
\end{tabular}

* test no. - inclination of chute - water content $(\%)$ - total start volume

according to

$m_{\mathrm{S}}=\frac{w}{1-w_{\mathrm{R}}} \rho_{\mathrm{S}} V$

$m_{f}=w \rho_{f} V-w_{\mathrm{R}} m_{\mathrm{S}}$,

where $\rho_{f}$ and $\rho_{\mathrm{S}}$ are the densities of water and solids.

\section{Test results}

\subsection{Test material}

An overview of the laboratory tests carried out with additional results is provided in Table 1 with the details of the single material mixtures according to the above naming convention. Sieve analyses of the natural test material were carried out to obtain information on the grain size distribution. Ninety percent of the grain sizes of the used material were smaller than $3 \mathrm{~cm}$ (Fig. 7); that is, the $d_{90}$ grain size was $3 \mathrm{~cm}$.

The water content was varied to obtain granular debrisflow fronts. The first test had a water content of $40 \mathrm{vol} \%$. It was found to be too small to obtain an adequate debris flow because the flow came to rest without reaching the net despite having the highest possible inclination of the chute. The next test was a very muddy-looking debris flow with a higher water content of $50 \%$. The subsequent tests all had a water content of $45 \%$ producing well-shaped and granular debrisflow fronts.

The flow heights decreased continuously from $30 \mathrm{~cm}$ at release down to $5 \mathrm{~cm}$ at around $4 \mathrm{~mm}$ close to the barrier.

\subsection{Retained volume}

The tests were started with a mesh size equal to the $d_{90}$ grain size in order to see whether the debris is retained or not. Based on the result, it could be decided whether and how to change the mesh size for the subsequent tests. In addition, the gap between the barrier and the riverbed was also chosen as $3 \mathrm{~cm}$, i.e. equal to the $d_{90}$ grain size. Both the mesh size and also the gap of $3 \mathrm{~cm}$ worked well and nearly all the debris was retained.

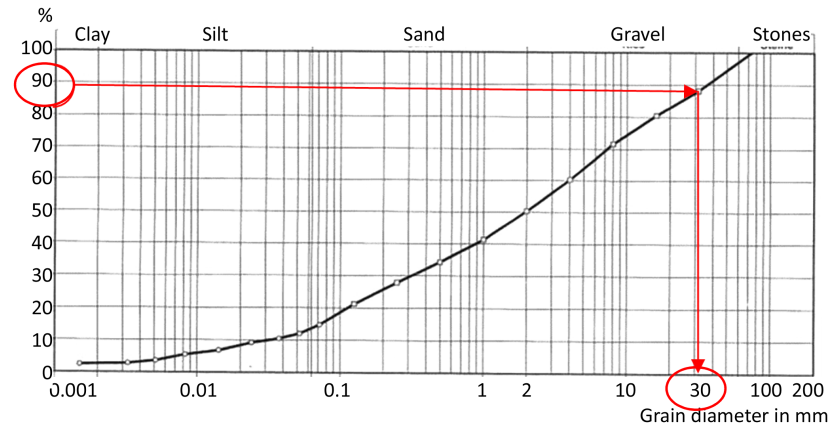

Figure 7. One of five sieving curves of the test material.

Afterwards bigger mesh sizes and bigger gaps were tested. With a wider mesh size of $4 \mathrm{~cm}$ about $80 \%$ of the debris at a $d_{90}$ grain size of $3 \mathrm{~cm}$ was still retained. The $6 \mathrm{~cm}$ mesh size still retained about two-thirds of the debris. With a $6 \mathrm{~cm}$ basal gap underneath the barrier with a $3 \mathrm{~cm}$ mesh sized barrier no debris was retained at all. The flow height in the chute of this test was $7 \mathrm{~cm}$ and all the debris passed beneath the barrier. Summarizing, a good retention effect of the barrier was achieved with a mesh size and basal gap equal to the $d_{90}$ grain size whereas the limit size of the mesh is twice the $d_{90}$ grain size. For details on mesh size and the basal gap, see Table 2 for the situation before and after the individual tests.

\subsection{Velocities and impact forces}

The velocity development of the $45 \%$ water content tests is shown in Fig. 8a. The 43, 44 and 45 (Table 2) test velocity profiles are quite similar. The $42-50-0.45-50$ velocity is missing because of a defect laser signal from the uppermost laser. Test 46 turned out to be an outlier because the velocity at the third laser is $4.5 \mathrm{~ms}^{-1}$ and consequently higher than the others with only $3 \mathrm{~ms}^{-1}$. The reason was identified by an increased percentage of fine material in the debris mixture because test 46 used the remaining material from the box which has been filled in the field and this rest contained more fine material.

The impact velocity was nearly the same in every test with $3.5 \mathrm{~m} \mathrm{~s}^{-1}$. In Fig. 8b a plot of the measured forces in function 
Table 2. Overview over the tests and the retained volume.

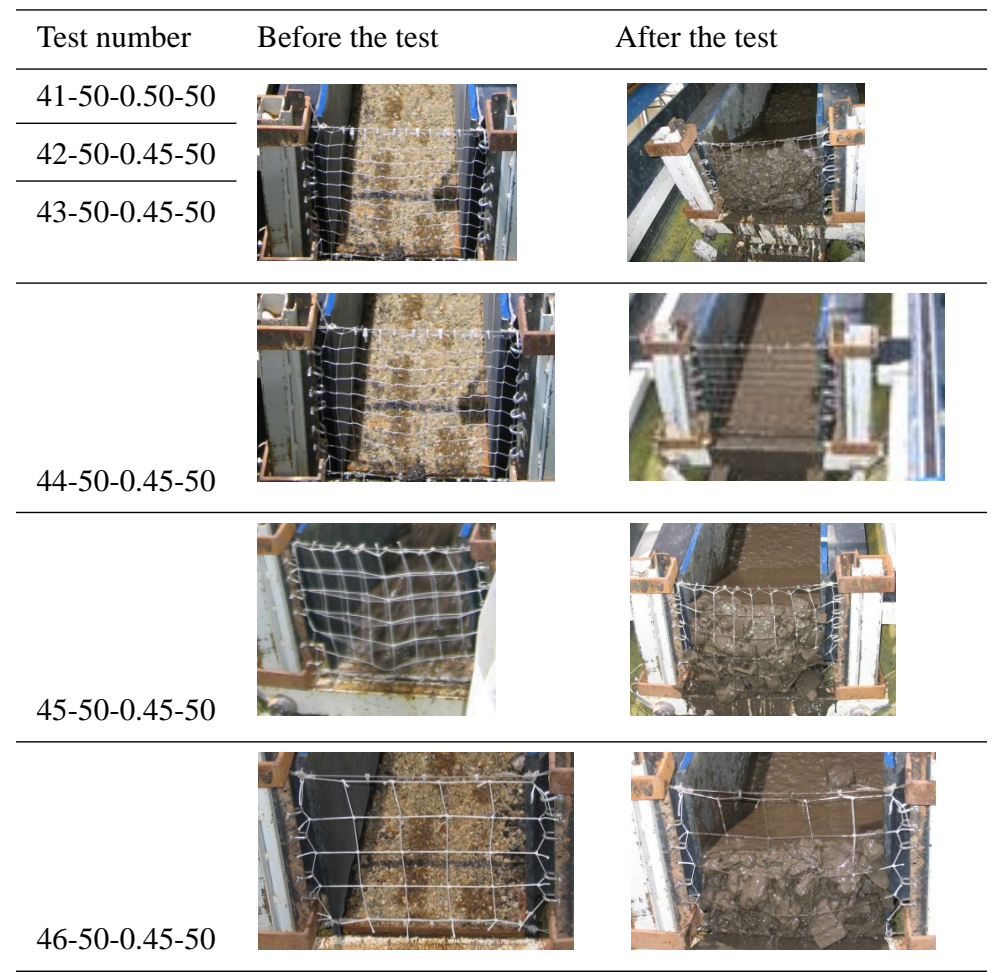
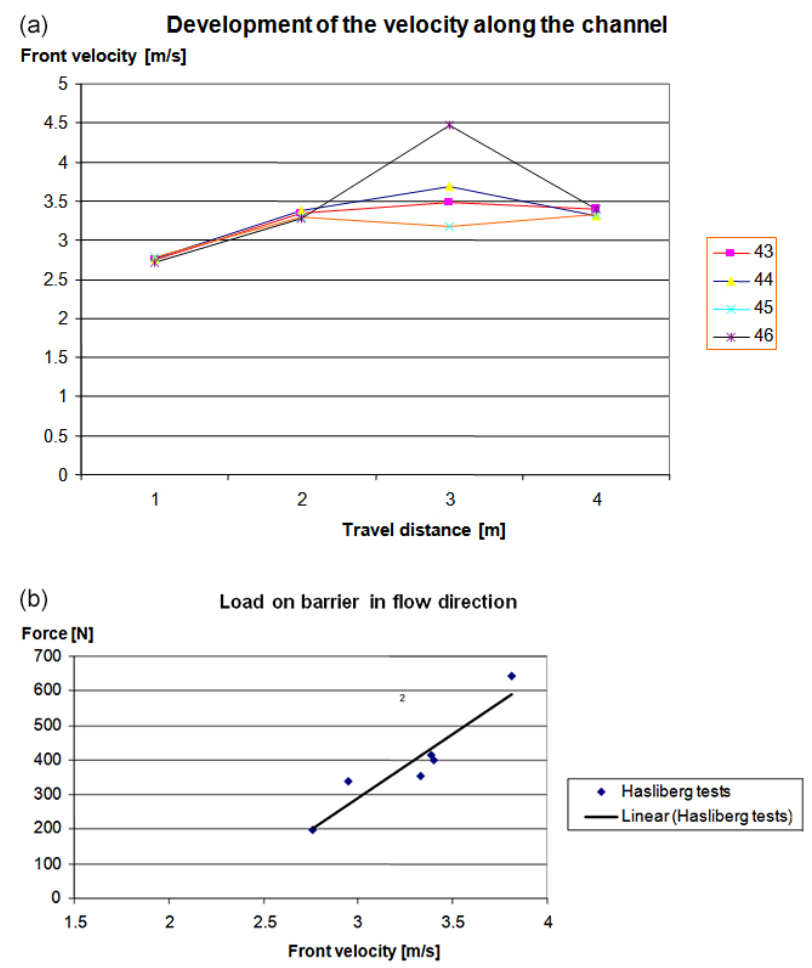

Figure 8. (a) Velocity profile along the channel length and (b) impact forces of the tests versus the impact velocities. of the impact velocity is shown. The highest impact force occurred in the second test with a water content of $50 \%$, and for this reason there was also a higher impact velocity. The six tests with material from the river Louwenen are too few to make a final statement regarding the relationship between impact forces and impact velocities, but it is obvious that higher impact velocities result in higher impact forces.

\section{Comparison with field conditions - scaling effects}

\subsection{Dimensional analysis}

If a physical model should reflect the natural processes on a scalable basis, the criteria for the geometric, kinematic, and dynamic aspects must be similar (Jirka, 2001). For each similarity special so-called dimensionless parameters can be defined reflecting the scaling between model and field. The geometric similarity is based on constant quotients; the kinematic and dynamic similarities are based on time-dependent variables such as accelerations, forces, velocities or impact durations. In general, it is difficult to fulfil all similarities but a compromise has to be found reflecting the relevant factors. For example, finding a dynamic force similarity is quite impossible because of the mostly unscalable internal friction values of the fluids used (Iverson, 2015).

The dimensional analysis is based on the input parameters relevant for a debris-flow impact process as shown in Table 3 (Wendeler, 2008). In total, 12 parameters were de- 
Table 3. Input parameters for a dimensional analysis.

\begin{tabular}{lll}
\hline Debris-flow parameters & Symbol & Dimension \\
\hline change of dynamic pressure & $\Delta P$ & {$\left[F / L^{2}\right]$} \\
average velocity & $u_{\text {front }}$ & {$[L / T]$} \\
average width of riverbed/barrier & $b$ & {$[L]$} \\
density of debris & $\rho$ & {$\left[F T^{2} / L^{4}\right]$} \\
relevant debris-flow volume & $V$ & {$\left[L^{3}\right]$} \\
gravitation & $g$ & {$\left[L / T^{2}\right]$} \\
kinematic viscosity & $v$ & {$\left[L^{2} / T\right]$} \\
inclination of channel & $\Theta$ & {$[-]$} \\
$d_{90}$ grain size & $d 90$ & {$[L]$} \\
flow depth/height & $h_{\mathrm{fl}}$ & {$[L]$} \\
\hline Interaction with the barrier & & \\
\hline residual height & & {$[L]$} \\
mesh size & $h_{b}^{\prime}$ & {$[L]$} \\
filling time & $M$ & {$[T]$} \\
\hline
\end{tabular}

fined regarding the 3 different dimensions of force $F$, length $L$ and time $T$. According to the Buckingham theorem (Buckingham, 1915) this results in the nine dimensional numbers listed in Table 4.

The number $\Pi_{1}$ is often called the drag coefficient in hydraulic engineering. It clarifies the stream pressure on an obstacle within a flow regime. $\Pi_{2}$ reflects the Froude number $F r$, which describes the quotient between internal and gravity-driven forces. It classifies the flow regime of open channel flow processes as opposed to the Reynold's number $R e$, which describes the quotient of mass-dominated forces compared to viscous forces in a pressured flow and is expressed by $\Pi_{3}$. However, a physical hydraulic model will never fulfil both numbers, i.e. Froude and Reynold, at the same time. $\Pi_{4}$ is related to the dynamic behaviour of the filling time compared to the different flow surges. $\Pi_{5}$ represents the nominal length of a debris-flow surge using the volume of the filling surge and the impacted section of the debrisflow net. $\Pi_{6}$ relates to the grain size distribution over the flow height of a debris flow and is estimated as a very important number to interpret the basal opening and mesh opening criteria. However, the $d_{90}$ grain size in a real debris flow or deposition zone is not easy to find. $\Pi_{7}$ is the quotient of the residual net height after the filling of the barrier to the flow height focussing on the number of filling steps for a complete filling of the barrier (Wendeler, 2008). $\Pi_{8}$ is the mesh opening size compared to the $d_{90}$ grain size describing the retention behaviour for different mesh sizes. $\Pi_{9}$ is the internal friction value of the material in a steady-state flow and is an important parameter for the energy balances of flow regimes.

The above dimensionless numbers have been classified in Table 4 according to their importance for the tests because not all numbers can be fulfilled at the same time. Table 4 also includes the results obtained for the different dimensionless numbers from more than 60 laboratory tests with material
Table 4. Dimensionless numbers for 70 debris-flow impact tests and from field measurements with classification $\mathrm{a}-$ important, $\mathrm{b}$ - less important, c - not relevant (Wendeler, 2008).

\begin{tabular}{lccc}
\hline Number & Laboratory & Field & Relevance \\
\hline$\Pi_{1}=\Delta P / \rho v^{2}$ & $0.1-1.0$ & $0.7-2.0$ & $\mathrm{a}$ \\
$\Pi_{2}=g h_{\mathrm{fl}} / u^{2}=1 / \mathrm{Fr}^{2}$ & $0.7-7.0$ & $0.4-4.0$ & $\mathrm{a}$ \\
$\Pi_{3}=v / u h_{\mathrm{fl}}=1 / R e$ & $100-1000$ & $600-10^{5}$ & $\mathrm{c}$ \\
$\Pi_{4}=t_{\mathrm{imp}} u / h_{b}^{\prime}$ & $0.8-18.0$ & $2.6-4.0$ & $\mathrm{a}$ \\
$\Pi_{5}=V /\left(h_{\mathrm{fl}}^{2} b\right)$ & $10-185$ & $120-700$ & $\mathrm{a}$ \\
$\Pi_{6}=d_{90} / h_{\mathrm{fl}}$ & $0.2-1.2$ & $2.0-10.0$ & $\mathrm{~b}$ \\
$\Pi_{7}=h_{b}^{\prime} / h_{\mathrm{fl}}$ & $1.5-7$ & $1.6-8$ & $\mathrm{a}$ \\
$\Pi_{8}=M / d_{90}$ & $0.3-2.0$ & 1.2 & $\mathrm{~b}$ \\
$\Pi_{9}=\tan \Theta$ & $0.25-0.5$ & $0.08-0.3$ & $\mathrm{c}$ \\
\hline
\end{tabular}

from the rivers Illgraben Trachtbach and from field events measured in Illgraben (Wendeler, 2008).

\subsection{Interpretation of dimensionless numbers for Hasliberg tests}

If gravitationally driven forces prevail in a flow regime and if the flow has a free water surface, the Froude number scaling is a reasonable possibility (Bollrich and Preissler, 1980). The Froude number $F r=u / \sqrt{g \cdot h \cdot \cos \alpha}$ (where $u$ is the centre front velocity, $g$ the acceleration due to gravity, $h$ the flow height and $\alpha$ the inclination of the riverbed) is proportional to inertial forces and characterizes the flow regime. If the number is below 1 the flow is subcritical, if it is 1 the flow becomes critical and bigger than 1 means a rapid flowing supercritical flow. For interpreting the laboratory model to the field, the Froude number ideally is similar for both the laboratory and the field for a free surface flow (Rickenmann, 1999; Weber, 2000; Iverson, 2015).

Table 5 lists the Froude numbers we obtained from the six laboratory tests ranging between 2 and 5 . Such numbers are rather high for debris flows (see Table 4). In the Swiss Illgraben Froude numbers ranging only $0.5-2$ were determined (B. McArdell, WSL, personal communication, 2015). The large laboratory Froude numbers developed due to the large inclination of the chute. However, the expected large discharge in the Milibach river delivers also a high Froude number of about 4 according to Schatzmann (2006). Thus, the Froude numbers of the laboratory tests are in the same range as expected for the field scenario and we therefore estimated our laboratory tests to correctly reflect the reality. This similarity now allows us to also transfer the geometrical relations from laboratory tests to the field.

Transferring the geometrical mesh parameters, the best mesh size can now be evaluated. Referring to a laboratory $d_{90}$ grain size of $3 \mathrm{~cm}$, which at the same time is the mesh size of the barrier, we obtain an ideal field mesh size of $30 \mathrm{~cm}$ based on an estimated $d_{90}=30 \mathrm{~cm}$ in the Hasliberg catchment (largest boulder found had a diameter of $1.2 \mathrm{~m}$ 
Table 5. Results of laboratory tests compared with design values in the field ( $Q_{\max }-\max$. discharge, $H_{\max }-\max$ flow height, $u_{\max }-\max$. front velocity, $\mathrm{Fr}$ - Froude number).

\begin{tabular}{|c|c|c|c|c|c|c|c|c|c|}
\hline & \multicolumn{3}{|c|}{$u_{\max }\left(\mathrm{ms}^{-1}\right)$} & \multicolumn{3}{|c|}{$H_{\max }(\mathrm{cm})$} & \multicolumn{3}{|c|}{$F r$} \\
\hline Milibach $^{\mathrm{a}}$ & \multicolumn{3}{|c|}{18} & \multicolumn{3}{|c|}{200} & \multicolumn{3}{|c|}{4.152} \\
\hline \multirow[t]{2}{*}{ Laboratory test no. } & \multicolumn{9}{|c|}{ Measurement at laser no. } \\
\hline & 1 & $\rightarrow$ & 3 & 1 & $\rightarrow$ & 3 & 1 & $\rightarrow$ & 3 \\
\hline 41 & 2.76 & $\rightarrow$ & 4.16 & 20 & $\rightarrow$ & 5 & 2.084 & $\rightarrow$ & 6.281 \\
\hline 42 & 3.78 & $\rightarrow$ & - & 4.5 & $\rightarrow$ & - & 6.016 & $\rightarrow$ & - \\
\hline 43 & 2.75 & $\rightarrow$ & 3.48 & 17 & $\rightarrow$ & 7.1 & 2.252 & $\rightarrow$ & 4.409 \\
\hline 44 & 2.77 & $\rightarrow$ & 3.68 & 22 & $\rightarrow$ & 6 & 1.994 & $\rightarrow$ & 5.072 \\
\hline 45 & 2.79 & $\rightarrow$ & 3.18 & 16 & $\rightarrow$ & 6 & 2.355 & $\rightarrow$ & 4.369 \\
\hline 46 & 2.71 & $\rightarrow$ & 4.47 & 19 & $\rightarrow$ & - & 2.099 & $\rightarrow$ & - \\
\hline
\end{tabular}

a design slope inclination $16.7^{\circ}$, max. discharge $100-150 \mathrm{~m}^{3} \mathrm{~s}^{-1}$

- no measurement

in Fig. 2). Therefore, we recommend that the mesh opening size for the best blocking effect ideally has $30 \mathrm{~cm}$. Experience from the field in the Swiss Illgraben (Wendeler, 2008) with mesh sizes of $30 \mathrm{~cm}$ and an estimated $d_{90}$ of $30-50 \mathrm{~cm}$ resulted in well-retained debris-flow material.

Looking at the basal opening, the distance between the channel bed and the lower support rope, it was found that $\Pi_{6}, \Pi_{7}$, and $\Pi_{8}$ are decisive and fulfil the requirements in a certain range in Table 4 . The best retention behaviour was achieved for a laboratory basal opening of $3 \mathrm{~cm}$ compared to a flow height of $5 \mathrm{~cm}$ in front of the barrier. Therefore it was recommended that a relationship between flow height $h_{\mathrm{fl}}$ and basal opening $h_{d}$ would be

$h_{\mathrm{fl}}=1.5 h_{d}$

for an optimized retention capacity of the barrier. This formula was also applicable to the Illgraben in 2006 where a basal opening of $0.5 \mathrm{~m}$ resulted in a good filling process for a flow height of $1 \mathrm{~m}$ at the debris-flow front (Wendeler, 2008).

\section{Conclusions}

The series of six laboratory tests with debris-flow material out of the Louwenenbach/Milibach at Meiringen/Hasliberg prove that it is possible to study the filling process and the retaining behaviour of the barrier depending on the mesh size. A reasonable result was found with both a net mesh size and a basal gap of $3 \mathrm{~cm}$. Almost all the debris material was retained even if $90 \%$ of the investigated debris material grain size was smaller than $3 \mathrm{~cm}$. The gap between the mesh and the channel floor also had a size of $d_{90}$ to retain the oncoming debris material. The results of the laboratory tests are helpful for the design and construction of new debris-flow barriers in the Hasliberg region.

In general, laboratory tests are always difficult to transfer to actual field conditions because of scaling problems
(Wendeler, 2008; Canelli et al., 2012; Iverson, 2015). However, a dimensional analysis provides suitable factors to scale the physical tests to the field. Adequate dimensionless numbers fulfil the geometric, dynamic or kinetic aspects having a similar range in the laboratory and in the field. In the actual case, Froude similarity has been used. Good retention of debris material is achieved with mesh opening sizes not bigger than $d_{90}$ grain size and the basal opening $h_{d}$ not bigger than $h_{\mathrm{fl}}=1.5 h_{d}$. These conclusions are based on the results of the actual tests, but other material tests produced similar results (Wendeler, 2008).

An interesting step would now be to study large-scale artificially released debris flows such as in South Korea (Paik, 2013). The sieving curves of the released material deliver the $d_{90}$ grain size and - if installed - the performance of a flexible barrier can be evaluated. This closure of the gap between small-scale and full-scale debris flows enables an improvement of the scaling procedures shown here.

The full design of barriers in the field as for example described in Volkwein (2014) or Wendeler (2008) can also be proven once again and verified and maybe optimized.

Edited by: A. Günther

Reviewed by: three anonymous referees

\section{References}

Bollrich, G. and Preissler, C.: Technische Hydromechanik Band 2, VEB Verlag für das Bauwesen, Berlin, Germany, 1980.

Buckingham, E.: Model experiments and the form of empirical equations, Trans. ASME, 37, 263-296, 1915.

Canelli, L., Ferrero, A. M., Migliazza, M., and Segalini, A.: Debris flow risk mitigation by the means of rigid and flexible barriers experimental tests and impact analysis, Nat. Hazards Earth Syst. Sci., 12, 1693-1699, doi:10.5194/nhess-12-1693-2012, 2012. 
Gubler, A.: Physikalische Modellierung von flexiblen Barrieren zum Schutz vor Murgängen, Master's thesis, ETH Zurich, Zurich, Switzerland, 2007.

Iverson, R.: Scaling and design of landslide and debris-flow experiments, Geomorphology 244, 9-20, 2015.

Jirka, G. H.: Einführung in die Hydromechanik, Universitätsverlag Karlsruhe, Karslruhe, Germany, ISBN 078-3-86644-158-3, 2007.

Monney, J., Herzog, B., Wenger, M., Wendeler, C., and Roth, A.: Einsatz von multiplen Stahlnetzbarrieren als Murgangrückhalt, Wasser, Energie, Luft, 99, 255-259, 2007.

Moriguchi, S., Borja, R. I., Yashima, A., and Sawada, K.: Estimating the impact force generated by granular flow on a rigid obstruction, Acta Geotechnica, 4, 57-71, 2009.

O'Brien, J. S. and Julien, P. Y.: Laboratory analysis of mudflow properties, J. Hydraul. Eng.-ASCE, 114, 877-887, 1988.

Paik, J.: Real-scale debris flow experiment in a mountain basin: releasing debris materials, available at: https://www.youtube.com/ watch?v=vIScSMtTY1Q (last access: 1 September 2015), 2013.

Rickenmann, D.: Empirical relationships for debris flows, Nat. Hazards, 19, 47-77, 1999.
Roth, A., Denk, M., and Zünd, T.: Bemessung, Milibach Meiringen, Murgangrückhalt Louwenenbach, flexible Murgangrückhaltesysteme, Technical report, Geobrugg AG, Romanshorn, Switzerland, 2006.

Schatzmann, M.: Rheometry for large particle fluids and debris flows, PhD thesis, ETH Zurich, Zurich, Switzerland, 2005.

Schatzmann, M.: Milibach Meiringen, Murgangrückhalt Louwenenbach, Technical report, Basler and Hofmann, Zurich, Switzerland, 2006.

Volkwein, A., Flexible debris flow barriers - Design and application, WSL Rep. Issue 18, ISSN 2296-3456, 29 pp., 2014.

Weber, D.: Experimente zum Fliess- und Erosionsverhalten von granularen Murgängen, $\mathrm{PhD}$ thesis, ETH Zurich, Zurich, Switzerland, 2000.

Wendeler, C.: Murgangrückhalt in Wildbächen - Grundlagen zu Planung und Berechnung von flexiblen Barrieren, $\mathrm{PhD}$ thesis, ETH Zurich, Zurich, Switzerland, 2008. 